\title{
Bridging Gaps: Libraries and Software Computing for MBAs
}

\author{
HILARY A. CRAIGLOW \\ Vanderbilt University, Nashville, TN \\ hilary.craiglow@owen.vanderbilt.edu \\ KELLY M. LAVOICE \\ Vanderbilt University, Nashville, TN \\ kelly.lavoice@owen.vanderbilt.edu
}

\begin{abstract}
Increasingly, data comes in large sets, and meaning must be derived by the user. Graduate business students and their future employers are looking for complementary computer programing knowledge to discover and display custom meaning from large sets of data. We present the context for graduate business programs and data analytics, the increasing need for knowledge of software computing and computer programing capabilities, and how libraries are well positioned to play a part in this data literacy. We also present a case study utilizing the Software Carpentries curriculum and lessons to provide a certificate program in software computing for graduate business students. Finally, we suggest opportunities for the academic business library community to further this work.
\end{abstract}

Keywords Data Analytics, Software Computing, Computer Programming, Coding, MBA, Python, SQL, R/RStudio, Data Literacy, Library Instruction, The Carpentries, Software Carpentry, MicroCredential

\section{Context: MBAs and Data Analytics}

Librarians understand that the amount of data, both freely available and commercially curated, is increasing exponentially. Researchers have long used various statistical methods and computer programs to work with datasets that come without structure or custom searchable interfaces. While some tools have a strong history in academic research, including SPSS, SAS, and Stata, new tools are being developed by vendors and open-educational communities to provide researchers with additional ways to analyze and find meaning in large datasets.

While several software programs are freely available to analyze the ever-expanding universe of data, a challenge is finding experienced analysts able to work with these tools to bring meaning to data and translate meaning into action. Datasets themselves may present trends or correlations, but a skilled analyst must also be able to communicate how data should be incorporated into strategies and business decisions.

MBA programs prepare students to succeed in a wide range of business roles; critical thinking is important for all the career paths students will pursue after graduation. Traditionally coveted roles, including those in long-established business spheres like consulting and investing, are becoming increasingly data-focused. An MBA graduate will likely interface with business analytics in almost any role they accept. For example, a manager in a non-technical role may be responsible for supervising data 
Ticker: The Academic Business Librarianship Review, 4:2 (2020)

http://doi.org/10.3998/ticker.16481003.0004.203

(C)2020 Hilary A. Craiglow and Kelly M. LaVoice

analysts. A successful manager needs to ensure that technical teams can communicate and collaborate with non-technical teams. Learning to speak the language of business analytics is critical for success.

In a November 2019 edition of Bloomberg Business Week, Professor Paul Oyer at the Stanford Graduate School of Business explains the importance for both data scientists and managers to be able to communicate and translate data issues to solve problems.

Managers have a ton of institutional knowledge and know how a business works, but they're sitting on troves of data that they don't know what to do with. And data people don't know what questions need to be answered through the data. The person who can go in the middle is becoming more and more valuable. (Cohen, 2019, para. 4)

In the Graduate Management Admission Council's (GMAC) 2018 Corporate Recruiters Survey, data and data analytics were front and center. "Overall, 71 percent of employers plan to place recent business school graduates into data analytics roles in 2018" (Graduate Management Admission Council, 2018, p. 5). If a student does not intend to pursue a data analytics role, it is likely they will work with data specialists in some capacity in their future career.

Business schools are aware of the needs of industry and employers and have looked to address the demand for data skills in a variety of ways. This paper is not a comprehensive curriculum review; others have tracked the increasing representation of data analytics courses in the MBA curriculum and seen the many ways in which business schools are working to incorporate these skills into student learning outcomes.

Warner (2013) provided a valuable overview of themes that should be taught in business analytics courses for MBA students and highlighted pedagogical resources from vendors. Warner stressed the importance of recognizing that using analytics to inform decision making is an iterative process that works best with a team of collaborators applying their own knowledge and expertise to the context at hand. While individual teaching tools and software programs continue to change and develop over time, Warner mentioned challenges faced in 2013 that academic professionals still face today; these include "access to data sets, faculty expertise, student aversion to statistics, finding a suitable textbook and cases, and staying current with practice" (Warner, 2013, p. 253).

Gupta, Goul, and Dinter (2015) recognized the demand for managers and analysts who can succeed in Business Intelligence (BI) \& Analytics roles. They reviewed course materials posted on Teradata University Network's web pages to develop a survey that was administered to participants at a BI event at the 2011 Americas Conference of Information Systems in Detroit, Michigan. Using feedback from 42 survey participants, mostly BI instructors, the authors developed a model curriculum to differentiate between the skills required in various programs. The authors discussed the differences among BI coursework for MBA, Master of Science (MS), and undergraduate programs:

MBA coverage predominantly focused more on strategically applying BI tools and technologies and solving business problems for competitive advantage, the MS coverage emphasized learning how to build BI applications using BI tools, and the undergraduate coverage focused on understanding BI and its tools for solving business problems. (Gupta et al., 2015, p. 452)

McCollum, Gheibi, and Doganaksoy (2019) highlighted the value of tools like R and JMP for exploratory data analysis in teaching business analytics in an MBA course. The authors used a dataset with qualitative and quantitative variables from the Federal Railroad Association. They concluded that 
Ticker: The Academic Business Librarianship Review, 4:2 (2020)

http://doi.org/10.3998/ticker.16481003.0004.203

(C)2020 Hilary A. Craiglow and Kelly M. LaVoice

"using a practical and relatable dataset, like the railroad incidents dataset that we have used for our analysis, motivates students' learning significantly" (McCollum et al., 2019, p. 137). The authors highlighted the value of using examples from industry to help make connections between academic study and business operations.

Some MBA programs are adding courses, as electives or requirements, that aim to teach both programming languages and data analytics skills. For example, Columbia Business School introduced two such credit-bearing courses in 2016: Introduction to Programming Using Python and Introduction to Databases for Business Analytics. According to Columbia, "by the end of the 2017-2018 academic year, one-quarter of full-time MBAs were learning how to code in either Python or SQL" (Kurczy, 2018, para. 17).

Other business schools have created new degrees to prepare students for future data-focused roles. The MIT Sloan School of Business offers a Master of Business Analytics. This 12-month program offers courses including From Analytics to Action, Communicating with Data, and Analytics Software Tools in R, Python, SQL, and Julia (MIT Sloan School of Business, 2020). NYU also offers a Master of Science in Business Analytics, a one-year, part-time program offering courses like "Foundations of Statistics Using R" and "Data-Driven Decision Making" (Leonard N. Stern School of Business, 2020). This program could be pursued by a student working full-time to prepare to take on additional data-focused work.

Business schools wishing to add data courses or programs face many challenges, such as meeting accreditation requirements, managing crowded curriculums, and hiring faculty to meet demand. This process is time-consuming and prescriptive. Another possibility of introducing business students to software computing involves partnering with other programs on campus, such as computer science departments or online learning extension programs.

MBA programs may allow students to take courses in other graduate programs on campus without pursuing dual degrees. Vanderbilt MBA students may take courses in other graduate programs, including computer science and data science. However, to be admitted entry into graduate courses in either program requires that students demonstrate sufficient training in a combination of programming techniques, calculus, statistical regression techniques, and/or other foundational computer science concepts. These courses are not intended to teach software programming to novice learners.

MBA students may look outside of their curricular studies to find learning opportunities to engage with software computing. Harvard University, for example, offers both freely available MOOCs and feebased Harvard Extension School courses that teach fundamentals of programming languages in a range of levels from introductory to advanced (Harvard University, n.d.). As of December 2019, Harvard offers four freely available MOOCs, which range from five weeks to 12 weeks. The Harvard Extension School offers two semester-long courses, Programming Languages and Web Programming with Python and Java Script. Both options could be utilized by students at other institutions looking for introductory programming courses that can be completed online while pursuing an MBA degree. For students looking for a brief introduction, wishing to understand broad capabilities of these programs and how they are utilized in business contexts, these courses may not be an ideal fit. We also recognize that costs associated with these programs can create barriers for students. There are vendors that will license and sell online learning modules that cover these topics to academic libraries; however, finding funds in library budgets to add new resources like this may be challenging, depending on other competing collection development priorities and budgetary pressures. 
Ticker: The Academic Business Librarianship Review, 4:2 (2020)

http://doi.org/10.3998/ticker.16481003.0004.203

(C)2020 Hilary A. Craiglow and Kelly M. LaVoice

Business librarians are in an excellent position to bring data analytics and software computing programming at an introductory level to their campus communities. Librarians have traditionally built an expertise in purchasing research data. This skillset ranges from reviewing licenses and technical requirements to marketing the datasets and helping researchers determine which datasets are most appropriate for solving research problems. In addition to our traditional expertise with finding, evaluating, and purchasing data sources, librarians have often been able to assist their campus communities by developing relevant programming relatively quickly. Library workshops and supplemental instruction supports the curriculum and exists alongside credit-bearing courses, which take additional time and resources to develop. Through our strong relationships with student, faculty, and staff stakeholders, we attempt to fill gaps in teaching and learning with timely, targeted programming. This ability to develop our own co-curricular courses, without going through a lengthy approval process, allows us to move quickly with implementing new offerings.

\section{Case Study: Walker Management Library}

In Spring 2019, the Walker Management Library, with the support of faculty, administrators, staff, and students, undertook a new initiative to support the growing interest in software and computing in Vanderbilt University's Owen Graduate School of Management. This effort developed after librarians noticed an increase in student requests to career services, faculty, and librarians for opportunities to use tools like Python or SQL for both school projects and career readiness. These conversations almost always acknowledged that top potential employers were looking for these skills and experiences with certain software programs and coding languages on resumes.

In our process of exploring how best we could make a meaningful impact in this area, we spoke with the deans of faculty and the MBA program about what was and was not represented in the curriculum. We wanted to be sure the program developed was co-curricular; our programming would complement and not compete with the curriculum. We recognized that the curriculum would change over time and, in turn, our library offerings would also evolve.

Before creating our Software Computing Certificate program, we had tested some brief low-barrier learning programs on data tools like Bloomberg and Capital IQ. In Fall 2017, we had added single classes on Tableau, R, Python, and SQL. These workshops always had strong attendance but were limited in time and scope. Fifty-minute introductory sessions set the context for why these programs were relevant and how they are being used in industry, but did not allow time to learn, work through sample data projects, and explore program capabilities in a cohesive manner.

The library had also sponsored various data working groups. Our Business Information \& Data Analysis Librarian sponsored the R Working Group, a time for students to collaborate and crowdsource ideas for data projects. While this group was open to any member of the Vanderbilt community, many Owen students attended. Additionally, our library fulfilled requests from faculty to provide support to students completing assignments that involved data analysis or some form of coding. For example, in Spring 2018, an Owen faculty member wanted to offer her students an opportunity to learn to webscrape static web content for a course assignment. The library was able to develop and offer two optional workshops in the weeks before the course assignment was due.

As relative novices in this area of data course design, we looked to partner with others who have tried- and-tested curricular materials. We found a good match with an organization outside of the library community, but with a deep commitment to supporting data needs in libraries and academia. Libraries 
Ticker: The Academic Business Librarianship Review, 4:2 (2020)

http://doi.org/10.3998/ticker.16481003.0004.203

(C)2020 Hilary A. Craiglow and Kelly M. LaVoice

have a rich tradition of sharing content, including research guides and lesson plans. Furthermore, professional organizations have routinely offered workshops and other learning materials for librarians to develop wide ranges of instructional content. The Carpentries (https://carpentries.org) is an organization that pulls together both concepts: collaborative program development and library training.

The Carpentries curates an international community of instructors who create and refine lessons on software and data tools that develop skills and literacy. Since 2012, Software Carpentry (https://software-carpentry.org) events have reached more than 34,000 researchers internationally (Software Carpentry, n.d.). The Carpentries collective develops curricula and lessons for two main tracks: software and data. The mission of the Carpentries is to build

global capacity in essential data and computational skills for conducting efficient, open, and reproducible research. We train and foster an active, inclusive, diverse community of learners and instructors that promotes and models the importance of software and data in research. We collaboratively develop openly-available lessons and deliver these lessons using evidence-based teaching practices. We focus on people conducting and supporting research. (Carpentries, 2020a)

The Software Carpentry was developed out of STEM (Science Technology Engineering Math), but sample lessons representing a variety of social science and humanities disciplines are in development (Carpentries, n.d.). Although not perfect in translation to business and finance, the core lessons in this area resonate well.

Content for the Software Carpentry programs varies, but the core lessons include: The Unix Shell, Version Control with Git, Programming with Python, Programming with R, R for Reproducible Analysis, Using Databases and SQL, and Programming with MATLAB. These are often organized into two-day workshops. While anyone may use the Carpentry curriculum under a Creative Commons Attribution License (CC_BY), only workshops taught by at least one certified Carpentry Instructor can be branded as an official Carpentry workshop (Carpentries, 2020b).

Many academic libraries have incorporated curriculum from the Carpentries into their services for both library staff and the campus community. The University of Oklahoma in Norman first brought the Software Carpentry workshop to their campus in 2014, as a partnership between campus IT and the University Libraries. Over 400 faculty, students, and staff from over 30 departments have attended their Carpentry programming. The University of Oklahoma joined the Carpentries organization, which allows 10 instructors per year to be officially certified. This method ensures sustainability, with the instructional workload spread across many potential instructors (Pugachev, 2019).

In 2017, a group of seven colleges and universities formed the New England Software Carpentry Library Consortium, piloting a consortial membership model with the Software Carpentry Foundation. This allowed the institutions to gain the benefits of being Carpentries members while sharing the membership cost. Initial members included Brown University, Dartmouth College, Harvard University, Mount Holyoke College, Tufts University, University of Massachusetts, Amherst, and Yale University. During the 20172018 pilot year, the Consortium's members hosted nine workshops across New England. Members of the group noted:

it was important to include staff from both libraries and information technology because we often provide complementary or joint services to support researchers' data needs. We needed to make sure that we could accurately and persuasively communicate the value of the Carpentries and the Consortium to our administrators. (Atwood et al., 2019, 3) 
Ticker: The Academic Business Librarianship Review, 4:2 (2020)

http://doi.org/10.3998/ticker.16481003.0004.203

(C)2020 Hilary A. Craiglow and Kelly M. LaVoice

Vanderbilt joined the Carpentries in partnership with the Office of the Vice Provost for Research. Like the New England Software Carpentry Library Consortium, we found that library staff must work closely with other groups on campus to support the complex research needs of our faculty and students. It is important to note that while our pilot Software Computing Certificate course incorporated many lessons from the formal Carpentries curriculum, and our main instructor was Carpentries-certified, we did not brand our program as a Carpentries workshop. In the Summer of 2018, Vanderbilt's Digital Scholarship and Communications department hosted a 2-day Carpentries-certified workshop for library staff. That program created new potential instructors for future library workshops targeting students, staff, and faculty as we work to build our Carpentries connections across Vanderbilt's campus.

In Spring 2019, we piloted our Software Computing Certificate program. The program was open to all graduate business students in the Owen Graduate School of Management. The course ran for 6 weeks during the spring semester, a lunch session and then 4 hours of instruction each Friday. In total, this course involved 24 hours of instruction. To maintain a high instructor-to-student ratio, we capped our pilot program to just 20 students. We opened registration at 8:30 a.m. on a Wednesday morning; by $8: 35$ a.m., the program was full. Within the hour, we formed a waitlist with 45 names. We quickly learned that there is a lot of interest in the topic and our students are willing to give up half of a day each week for six weeks to participate. While students did not earn credit towards their degree requirements, we did offer a certificate and online badge upon completion.

The effort took a significant amount of staff time. Each workshop had one instructor who used the Carpentries curriculum, and two, sometimes three, helpers who followed along and helped students who lagged behind during instruction or exercises. In this model, the instructor can focus on delivering the lesson, and helpers can troubleshoot with a participant without holding up the entire class.

The primary instructor for the course was our Business Information and Data Analysis Librarian. In addition, one session was taught by the Director of Research Computing and another by the library's Data Curation Specialist. Helpers included our Librarian for Geospatial Data and Systems and Librarian for Copyright and Scholarly Communications. It was a cross-campus team effort.

Our curriculum is outlined below:

\section{Program Launch}

The program was launched with opening remarks from our Career Management Director, who discussed how valuable these skills would be on resumes. Additionally, there was an introduction to the program, syllabus, lessons, workshop process, software, and code of conduct.

\section{Command Line and Shell}

The Unix shell allows people to do complex things with just a few keystrokes and automate repetitive tasks. Use of the shell is fundamental to using a wide range of other powerful tools and computing resources (including "high-performance computing" supercomputers).

III. Version Control, Sharing and Reproducing Code

Version control is the cornerstone of the digital world; it's what professionals use to keep track of what they've done and to collaborate with other people. Every large software development project relies on it, and most programmers use it for their small jobs as well. 
Ticker: The Academic Business Librarianship Review, 4:2 (2020)

http://doi.org/10.3998/ticker.16481003.0004.203

(C)2020 Hilary A. Craiglow and Kelly M. LaVoice

\section{Python Part I \& II}

This section provided an introduction to Python, the popular open-source programming language. Jupyter Notebook was used and covered.

\section{Databases \& SQL Part I \& II}

Three common options for storage are text files, spreadsheets, and databases. Databases include powerful tools for search and analysis and can handle large, complex datasets.

Students were required to participate in the first three lessons, plus lesson 4 or 5, in order to qualify for a certificate. Most enrolled students were able to successfully complete these requirements. After the course, students were given an opportunity to provide feedback via an anonymous Qualtrics survey. Students were asked about the value of each individual lesson. When asked to rank the lessons in order of importance, SQL came out first, followed by Python, Command Line/Shell/Bash and Version Control/Code Sharing/Git.

The open-ended questions provided valuable feedback on the student experience. When asked "What part of the lessons worked well?," students spoke to the value of the instructors and the value of active learning. When asked "What part of the lessons didn't work well?," answers spoke to an aversion to long periods of lecture time or exercises that involved following examples verbatim. Additionally, a student mentioned that they desired an opportunity to work on a project through each lesson. To quote: "It would have been nice to work on a project through each of the lessons. I feel like we learned the capabilities of these languages, but I'm not sure I could work on a project or get a job done." The same sentiment came up in an answer to a later question.

A supplementary issue presented itself in answers to multiple survey questions: the challenge of pacing the class. While some students came in with a basic knowledge of at least one coding language, some had no prior experience. While having additional helpers aims to ensure students who need additional support can have it without involving the entire class, we recognize that a one-size-fits-all class is challenging. Pugachev (2019) mentioned similar feedback from students at the University of Oklahoma. Given the nature of the work involved in teaching this 24-hour course, at this time it is unrealistic for the library to sustain offering an introductory and intermediate version of the course.

\section{Moving Forward: Opportunities}

As we look towards the future, we have identified three areas in which we hope to expand our course offering.

Barring finding a prepackaged business-focused curriculum as flexible as the Carpentries curriculum and instructor community, we first want to identify business datasets that can be integrated into the lessons. While the Carpentries team is working on an Economics curriculum that would likely be relevant, we think we can identify business datasets in our current collections, available online, or from faculty research projects that can be used in lessons. These examples can be designed to reflect projects that students may be asked to work on as consultants or in other business-focused roles. We can use our expertise of finding and evaluating datasets to identify potential resources and formats that would work best for the lessons in our course. Ideally, all examples will come from open-source material. We recognize the value of utilizing materials that can be shared with business librarian colleagues at other institutions. Like business schools, we believe that case-study-based learning will only enhance the value of our course. 
Ticker: The Academic Business Librarianship Review, 4:2 (2020)

http://doi.org/10.3998/ticker.16481003.0004.203

(C)2020 Hilary A. Craiglow and Kelly M. LaVoice

While we continue to explore new curricular materials and course structures for our Certificate Program, it is important to acknowledge that our current course is not built to scale to reach all current students in the Owen Graduate School of Management. By licensing online learning materials like O'Reilly for Higher Education, we can ensure students waitlisted for our course can engage in self-study with high quality resources. This will also allow for students unable to complete our certificate course to gain the skills they will need to collaborate with peers in our software working groups and on special projects.

Additionally, we want to provide students with an opportunity to build on the skills gained during the introductory course. Students expressed a desire for relatable projects that would allow them to put their skills into practice. We plan to reach out to faculty members in the business school to identify a faculty partner who will provide students with access to a dataset and allow them to assist with data analysis. In the future, we may explore expanding this opportunity by identifying companies that utilize our students for internships and case competitions who can provide students with a real-life problem that can be solved with data analysis. We would work closely with our Career Services Department, as well as our centers for Social Enterprise and Entrepreneurship, to identify these potential partners.

Finally, we hope to help students continue to build and sustain their own student learning networks, building coding communities of practices. As with learning any language, conversation is critical. While we host working groups for specific programming languages, such as $\mathrm{R}$ and Python, we can encourage students who complete the Software Computing Certificate program to continue collaborating as a cohort.

We welcome other business and data library colleagues to connect with us as we continue building our Software Computing Certificate program at the Owen Graduate School of Management. We aim to make our course as relevant as possible to our MBAs, offering students an introduction to software computing programs and connecting them with resources and projects that they can use to continue independent or cohort-based project work. Additionally, we hope to engage librarians with little prior software computing or programming experience to explore the possibilities of teaching this valuable content. We recognize that the curricular materials from the Carpentries have a tradition of being used to teach both students and fellow instructors, and our course would be just as beneficial to library staff as it is to MBA students.

Libraries have a rich history of teaching students how to use information, data, and complementary tools. Software computing is a natural progression of how business libraries prepare students for realworld business applications. Librarians have the capability to provide students with an introduction to the software skills they need to be successful working with data and with data scientists. As data analysis continues to grow as a skillset desired by all industries, we hope to continue to grow our capacities to support student learning in this area. 
Ticker: The Academic Business Librarianship Review, 4:2 (2020)

http://doi.org/10.3998/ticker.16481003.0004.203

(C)2020 Hilary A. Craiglow and Kelly M. LaVoice

\section{References}

Atwood, T. P., Creamer, A. T., Dull, J., Goldman, J., Lee, K., Leligdon, L. C., \& Oelker. S. K. (2019). Joining together to build more: The New England Software Carpentry Library Consortium. Journal of eScience Librarianship, 8(1), e1161. https://doi.org/10.7191/jeslib.2019.1161

The Carpentries. (2020a). About us. Retrieved from https://carpentries.org/about/

The Carpentries (2020b). What is a Carpentries workshop? Retrieved from https://carpentries.org/workshops/

The Carpentries. (n.d.). Community developed lessons. Retrieved from https://carpentries.org/community-lessons/

Cohen, Arianne. (2019, November 5). Every MBA needs tech skills--not just those headed for Silicon Valley. Bloomberg Business Week. Retrieved from https://www.bloomberg.com/news/articles/2019-11-05/businessschools-bridge-gap-between-managers-and-data-scientists

Graduate Management Admission Council. (2018). Corporate recruiters survey report 2018. Retrieved from https://www.gmac.com/market-intelligence-and-research/research-library/employment-outlook/2018-corporaterecruiters-survey-report

Griffel, M. (2018). The new languages of business: Python, SQL, R. Ideas and Insights. Retrieved from https://www8.gsb.columbia.edu/articles/ideas-work/new-languages-business-python-sql-r

Gupta, B., Goul, M., \& Dinter, B. (2015). Business intelligence and big data in higher education: Status of a multiyear model curriculum development effort for business school undergraduates, MS graduates, and MBAs. Communications of the Association for Information Systems, 36, 449-476. https://doi.org/10.17705/1CAIS.03623

Harvard University. (n.d.). Online Python courses. Retrieved from https://online-learning.harvard.edu/subject/python

Kurczy, S. (2018). MBAs who code. Ideas and Insights. Retrieved from https://www8.gsb.columbia.edu/articles/ideas-work/mbas-who-code

McCollum, J., Gheibi, S., \& Doganaksoy, N. (2019). Introducing advanced exploratory data analysis tools in an MBA program. Global Journal of Business Pedagogy, 3(1), 125-138.

Leonard N. Stern School of Business. (2020). Course Index. Retrieved from https://www.stern.nyu.edu/programsadmissions/ms-business-analytics/academics/course-index

MIT Sloan School of Management. (2020). Master of Business Analytics Curriculum. Retrieved from https://mitsloan.mit.edu/master-of-business-analytics\#curriculum

Pugachev, S. (2019). What are "The Carpentries" and what are they doing in the library? portal: Libraries and the Academy, 19(2), 209-214. https://doi.org/10.1353/pla.2019.0011

Software Carpentry. (n.d.). About us. Retrieved from https://software-carpentry.org/about/

Warner, Janice. (2013). Business analytics in the MBA curriculum. Proceedings of the Northeast Business \& Economics Association (pp. 251-254). 